\title{
The Parallel Evolution of Search Engines and Digital Libraries: their Convergence to the Mega-Portal
}

\author{
Uri Hanani \\ Information Science Department, Bar-Ilan University, ISRAEL, uri2@ netvision.net.il \\ Ariel J. Frank \\ Mathematics \& Computer Sciences Department, Bar-Ilan University, ISRAEL, ariel@cs.biu.ac.il
}

\begin{abstract}
The information era has brought with it the well-known problem of 'Information Explosion'. There are many and varied Search Engines (SES) on the Internet but it is still hard to locate and concentrate only on materials relevant to a specific task. Digital Libraries (DLs) could better provide such services on the Web. However, DLs have been much less researched and implemented than SEs. In any case, there is a real need to formulate a methodology for the understanding of both these types of Web data repositories, and especially of digital libraries. In this paper we classify both SEs and DLs using similar criteria on both a functional scale and a generational time-line. In particular, we introduce the idea of the third generation Harvested $D L(H D L)$ and its resulting DL harvesting model. The DL harvesting model was implemented in the 'Katsir' DL prototype system. Until recently, SEs and DLs were seen as completely separate paradigms dealing with building Web data repositories. By comparing them here and analyzing their characteristics, we discover that they actually share much in common. Our main objective here is to better understand what SEs and DLs really are, and what was the parallel evolution of SEs and DLs in the existing three generations. Finally, we note the expected incorporation of intelligent techniques and knowledge management in fourth generation SEs and DLs and the expected convergence of their interfaces and structures in the fifth generation, coined the MegaPortal. This concept generalizes all the features and characteristics expected to be found and implemented in the future Web Repository.
\end{abstract}

Keywords: Internet, Web, Data Repositories, Information Retrieval, Search Engines, Digital Libraries, Harvested Digital Library, Portals, Knowledge Management

\section{Introduction}

The information era has brought with it the wellknown problem of 'Information Explosion'. There are many and varied Search Engines (SEs) on the Internet but it is still hard to locate and concentrate only on materials relevant to a specific task. Also, it is not easy to get unique services usually provided by a regular library, for example: advice in locating materials, a guided tour of an existing data repository, or extraction of metadata, such as title, authors, keywords and summary.

Digital Libraries (DLs) could better provide such services on the Web. However, DLs have been much less researched and implemented than SEs. In any case, there is a real need to formulate a methodology for the understanding of both these types of Web data repositories, and especially of digital libraries.

In this paper we try to classify both SEs and DLs using similar criteria on both a functional scale and a generational time-line. This allows us to better understand their parallel evolution over time. Until recently SEs and DLs were seen as completely different paradigms dealing with building Web data repositories. By comparing them and analyzing their characteristics, we discover that they actually share much in common. Our main objective here is to better understand the following points:

1. What is really a SE and what are its different types and characteristics.

2. What is really a DL and what are its different types and characteristics.

3. The parallel evolution of SEs and DLs in the existing three generations.

4. The expected next generations of SEs and DLs and their convergence trend.

This article is structured as follows. The next section concentrates on data repositories and search on the Web by way of contrasting the use and development of SEs and DLs. The section following discusses SEs paradigm. The next section is devoted to the DLs and their emergence as a new paradigm. The before to last section discusses the parallel evolution of SEs and DLs generations. The following section forecasts the generations that will follow and their characteristics. We conclude the article with future directions.

\section{Data Repositories in the Web}

Following the introduction, this section aims to provide a general overview of various aspects and issues related to data repositories and information search on the Internet. After introducing and contrasting shortly SEs 
[1] to DLs [2, 3, 4, 5], we review in the next sections their parallel historical and functional evolution.

\subsection{What is a Search Engine}

The Internet and the Web have been growing in leaps and bounds over the past few years, accelerating the problem of information explosion. According to Nature [6], the publicly indexable Web contains an estimated 800 million pages as of February 1999, encompassing about 15 terabytes of information or about 6 terabytes of text after removing HTML tags and comments. An updated research [7] estimated that the Web has 2.1 billion unique pages and will double in size to four billion pages be early year 2001 .

Indeed, the growing amount of SEs that have popped up everywhere, reaching more than 3450 different SEs (www.searchengineguide.com). In accordance to the InvisibleWeb.com (http://www.searchability.com/) there are over 10,000 databases, archives, and SEs. All these tools enable us to access the cyberspace, but they also flood us with vast amounts of irrelevant information. Search engine coverage, relative to the estimated size of the publicly indexable Web, has recently decreased substantially, with no engine indexing more than about $16 \%$ of the estimated size of the publicly indexable Web.

In any case, since the Web data objects are scattered all over the Web, SEs are needed to bring them together through use of metadata structures. Before we delve more into the classifications of search engines, we should define more clearly the notion of a search engine in general.

Search engines were composed, in general, of the following three components:

1. Various robots or humans that roamed the net in search of resources worthy of reference.

2. Various databases containing metadata $[8,9]$ on all the referenced resources. These metadata databases could be full-text indices, keyword indices, directories or topics-trees, or other similar metadata structures.

3. A SE interface/tool that enables the SE clients to launch a basic search on the SE's database and get back a list of web pages of (supposedly) relevant resource URLs, or to recursively descend the branches of the SE's directory in search of sites of interest.

There have been a few attempts to classify SEs. For example, in [10], search engines fall into five categories: robotic Internet search engines which use a Web robot to retrieve a significant number of documents from the World Wide Web; mega-indexes which have links to the robotic search engines; simultaneous megaindexes which access the robotic search engines simultaneously; subject directories which are manuallymaintained collections of Web sites organized by topic; and robotic specialized search engines which focus on a small or specialized segment of the Internet.

\subsection{What is a Digital Library}

In any case, the Web and the SEs do not substitute for the loved, classical libraries. No one questions or disputes the long and lasting contribution of existing classical libraries. The concept of the paper library and the various services it provides are well established. The idea is that DLs should provide all these and more [11, 12]. We use the term 'integrated services' in DLs to allude to that. These integrated services will add services that are made possible by use of the digital medium such as: varied search techniques resulting in focused results, faster provision of relevant resources, and access also to multimedia resources.

The problems of regular libraries are well known and need not be detailed here. On the other hand, it is less clear to us what a DL is and how it works. So before we delve more into the classifications of DLs, we should define the notion of a library in general and of DL specifically.

Adam \& Yesha [13] combined the DL definition with E-Commerce describing them both as "... support the creation of information sources and the movement of information across global networks". They characterized the DL as "a collection of distributed autonomous sites (servers) that work together to give the consumer the appearance of a single cohesive collection". A more functional approach to characterize the DL is given by Fox \& Marchionini [14]: "collaboration support, digital document preservation, ..., information filtering, information retrieval, instructional modules, intellectual properties rights management, multimedia information services, question answering and reference services, resource discovery, and selective dissemination of information". Chen \& Houston [4] emphasize the four components that should reside in the DL as follows:

1. Creating digital library content

2. Including and filtering information

3. Supporting universal access

4. Preservation

The DLF (Digital Library Federation) crafted the following definition, stressing the need to achieve the need to "federating" several DLs [15, 16], as follows: "Digital libraries are organizations that provide the resources, including specialized staff, to select, structure, offer intellectual access to, distribute, interpret, preserve the integrity of, and ensure the persistence over time of collections of digital works". All the above definitions are very general. Consequently, we specifically define a library as having six major characteristics:

\section{1) Collection of data objects -}

A library holds together a collection of data objects, items and resources. The items can be:

○ Books, journals and documents (e.g., HTML pages). 
- Multimedia objects (such as pictures or images, tapes or video files, etc.).

- The library objects can be available locally, or indirectly, by using a network to access them.

2) Collection of metadata structures -

A library contains a collection of metadata structures, such as catalogs, guides, dictionaries, thesauri, indices, summaries, annotations, glossaries, etc.

3) Collection of services -

A library provides a collection of services, such as:

- Various access methods (search, browse, etc.) for as well as consultation for different users.

- Management of the library (purchase, shelf arranging, computerization, communication).

○ Logging/statistics and Performance Measurement Evaluation (PME).

- Selective Dissemination of Information (SDI) or as it is called Push mode on the Internet.

4) Domain focus -

A library has a domain focus and its collection has a purpose. For example: art, science, or liter ature. Also, it is usually created to serve a community of users, and therefore is finely grained.

\section{5) Quality control -}

A library uses quality control in the sense that all its material is verified and consistent with the profile, of the library. The materia $l$ is filtered, and also its metadata is usually enriched (e.g., annotated).

\section{6) Preservation -}

The purpose of preservation is to ensure protection of information of enduring value for access by present and future generations. Preservation includes the allocati on of resources for preservation, preventive measures, and remedial measures to restore the usability of selected materials.

\subsection{SEs vs. DLs}

The SE paradigm and the DL one are really located at the extremes of a spectrum of data repositories and types of Web search. They are two sides to each of these coins: the data repository construction (server) side and the user (client) information search side. We now discuss and contrast these aspects.

As regards to the construction of a SE, this is a complex undertaking. It is clearly a long -term effort that is (eventually) supported by commercial companies. The SE aims to build a quantitative global repository that represents as much information available on the Internet as possible or at least a large amount of it. The SE maintains various data structures to represent its repository, like indices, directories and catalogs. It also provides basic and advanced user interfaces for search purposes. The SE continuously employs various types of robots to search out and index or summarize pages on the Internet and to dynamically update its provided repository. Advanced SEs use a variety of sophisticated artificial intelligence techniques and natural language processing algorithms to gather and organize their contents.

Let us look now at the user side of SEs. Assume that a user needs some information on a certain topic that is currently of interest. So the user summons on a whim his favorite SE to search for any relevant information. The SE is invoked with an ad -hoc query, composed of a supposedly appropriate combination of keywords. The SE will certainly return a lot of noisy information (with low precision and recall) that is bound to overload the user. The user will then have to tediously sift through it all and manu ally filter the supplied references. The relevant information found will then be immediately consumed or temporarily kept in a cache for a short-term period.

Consider now the process of constructing a DL. A user, says an information scientist, realizes a wellthought out need to build a qualitative data repository on an important focused topic. The information scientist decides to invest by constructing and maintaining a long term DL, described by a set of specific categories. So he/she interacts with a special interface to carefully define his/her DL request. The DL is then gathered and made available to its users. It supports various data structures to enable efficient keywords search, touring a DL via a topics-tree, and DB/SQL oriented meta views of the DL contents. The contents of the DL are continuously kept current and can be annotated and enhanced with additional relevant material.

Let us check now on the use of DLs. A serious user will tend to often need information on a topic of interest. So he/she invokes the high-level DL interface and chooses an appropriate way to search this previously constructed DL. The DL will return a reasonable amount of information that the user can readily digest. The relevant information can be further annotated by the us er and later rediscovered whenever needed.

So, to summarize, SEs necessitate a huge organizational effort, provide the user with too much noisy information, but are useful for one -time shots for quickly needed information. DLs, on the other hand, require a modest support effort, excel in quality and ease of use, provide the user with focused information, but have to be made available beforehand. It is important to note that these two paradigms are neither conflicting nor exclusive, but are complementary in nature. In fact, both SEs and DLs have a lot of similarities in their evolution patterns, as described in the following sections.

\section{The Search Engines Paradigm}

Search Engines are perhaps the most popular service in the Internet. In this section, we des cribe the evolution line that the SEs have taken over three generations (see table 1). The first generation of SEs, referred to as BSEs for Basic-SEs, provided basic metadata structures that were used to query the Web. 
There were basically two types of Basic-SEs in the first generation of SEs:

1) Indices that built a comprehensive index using various robots (also called crawlers, ants, worms, spiders, etc.). Indices are computer-created and are search oriented.

2) Directories (also called guides, catalogs, weblogs, etc.) that built a topics-tree based on categories. Directories are mostly humanly-compiled and are browse oriented.

Both Basic-SEs, indices and directories, can be further classified as being general or specialized. A General SE has a wide coverage of diverse topics. On the other hand, a Specialty SE focuses on a domain, target audience or on a specific media type.

So for indices we have the following division:

1) General Index (GI) - representative general indices $[1,17]$ include, for example, Alta Vista, Infoseek, Lycos, HotBot, Excite, WebCrawler, Northern Light and Snap.

2) Specialty Index (SI) - representative specialty indices [1, 17] include, for example, Bidfind that focuses on the online auction domain (http://www.bidfind.com/), MedHunt for medical information (http://www.hon.ch/MedHunt/), Travel-finder that is geared for travelers (http://www.travel-finder.com/) and Scour.Net for multimedia types (http://scour.net).

Similarly, for directories we have (see: http://www.searchpower.com/,http://www.allsearchengin es.com/, http://www.searchenginewatch.com/):

1) General Directory (GD) - representative general directories include, for example, Yahoo, LookSmart, Open Directory, Internet Public Library (IPL), WWW Virtual Library (Vlib), CyberDewey (http://www.lm.com/ mundie/CyberDewey/CyberD ewey.html) and SearchIQ.

2) Specialty Directory (SD) - representative specialty directories include, for example, Med411 as a directory about the medical world (http://www.med411.com), the Comfind business directory (http://comfind.com/), and various search directories for search engines such as Colossus (http://www.searchenginecolossus.com/) and Search Directory (http://disastercenter.com/search/engines.htm ).

The second generation of SEs, referred to as MSEs for Meta-SEs, put the emphasis on easier methods for the locating of web resources, on procedures for reducing the accumulated results, and on better ranking.

A MSE could employ a score of basic-SEs that provide the raw search results that are to be merged and ranked by the MSE so as to present a unified list of search results to the inquiring user. Representative second generation Meta-SEs include, for example, MetaCrawler, SavvySearch, Search.Com and DogPile [17]. See also a list

at

SearchIQ

SE

(http://www.searchiq.com/directory/multi.htm ) for many more MSE.

The third generation of SEs, referred to here as PSEs for Popularity-SEs (also Parallel or Portal), put the emphasis on supporting both an index and a directory, on various advanced techniques and services, such as enrichment of the SE databases by user initiatives and feedback, and on higher quality and faster search results.

For example, Google and IBM's Clever SEs [18] apply link popularity measures, and DirectHit applies usage and time popularity measures, to determine the relevancy and ranking of Web pages. As another example, FAST provides parallel search services based on advanced search algorithms. Recently, FizziLab introduced contextual technology (http://www.fizzylab.com/) that identifies relevant connections in real-time, and displays them to the users.

Table 1 - The Three Generations of Search Engines

\begin{tabular}{|c|c|c|c|}
\hline $\begin{array}{c}\text { Jeneratior } \\
\text { No. }\end{array}$ & SEs & Features & Examples \\
\hline 1 & $\begin{array}{l}\text { Basic- } \\
\text { SEs }\end{array}$ & $\begin{array}{l}\text { Includes Robots, } \\
\text { Indices, Directories, } \\
\text { basic/advanced user } \\
\text { interfaces }\end{array}$ & $\begin{array}{l}\text { Yahoo, } \\
\text { LookSmart, } \\
\text { Open } \\
\text { Directory, } \\
\text { Excite, Lycos, } \\
\text { HotBot, } \\
\text { InfoSeek }\end{array}$ \\
\hline 2 & $\begin{array}{l}\text { Meta- } \\
\text { SEs }\end{array}$ & $\begin{array}{l}\text { Multi and mega } \\
\text { search }\end{array}$ & $\begin{array}{l}\text { MetaCrawler, } \\
\text { SavvySearch, } \\
\text { DogPile }\end{array}$ \\
\hline 3 & $\begin{array}{l}\text { Popular } \\
\text { ity-SEs }\end{array}$ & $\begin{array}{l}\text { Popularity based on } \\
\text { links, usage and time } \\
\text { measures, Parallel, } \\
\text { Portal }\end{array}$ & $\begin{array}{l}\text { Google, Clever, } \\
\text { DirectHit, } \\
\text { FAST, } \\
\text { FizzyLab }\end{array}$ \\
\hline
\end{tabular}

\section{The Digital Libraries Paradigm}

Not many references that classify digital libraries can be found. One known classification (see: http://sunsite.berkeley.edu/Libweb/) is by organizational or geographical division: Academic, Public, National, State, Regional, Special and School Libraries.

In this section, we describe the evolution line that the DLs have taken over three generations (see table 2). The first generation of DLs, referred to as Stand-alone Digital Library (SDL), is the regular classical library implemented in a fully computerized fashion. SDL is simply a library in which the holdings are digital (i.e., electronic - scanned or digitized). The SDL is self contained - the material is localized and centralized. In fact, it is a computerized instance of the classical library with the benefits of computerization.

There were basically two types of SDLs in this first generation (see figure 2): General (or Several) SDL and Specialty (usaually Single) SDL. Examples of 
general SDLs are the Library of Congress (LOC) and its National Digital Library (NDL) ( http://www.loc.gov), Alexandria Project (http://alexandria.sdc.ucsb.edu/) and the Israeli K12 Portal Snunit (http://www.snunit.k12.il). Examples of Specialty SDLs are the Making of America (MOA http://moa.umdl.umich.edu/ ), Booklist (http://www.ala.org/booklist/index.html), ACM DL (http://www.acm.org/dl/), Alex (http://sunsite.berkeley.edu/alex/) and many others.

The second generation of DLs, referred to as Federated Digital Library (FDL, is a federation of several independent SDLs in the network, organized around a common theme, coupled together on the network. A FDL composes many autonomous SDLs that form a networked library with a transparent user interface. The different SDLs are heterogeneous and are connected via communication networks. The major challenge in the construction and maintenance of a FDL is interoperability (since the different repositories use different metadata formats and standards). Examples of FDLs are the Networked Computer Science Technical Reference Library (NCSTRL) (http://www.ncstrl.org,) Networked Digital Library of Theses and Dissertations (NDLTD) (http://www.ndltd.org), and Stanford InfoBus (http://walrus.stanford.edu/diglib/) [19].

The coming third generation of DLs, referred to as Harvested Digital Library (HDL), is a virtual library providing summarized access to related material scattered over the network. A HDL holds only metadata with pointers to the holdings that are "one click away" in Cyberspace. The material held in the libraries is harvested (converted into summaries) according to the definition of an Information Specialist (IS). However, a HDL has regular DL characteristics, it is finely grained and subject focused. It has rich library services, and has high quality control preserved by the IS, who is also responsible for annotating the objects in the library. Initial examples of HDLs are the SourceBan k software development library ((http://www.sourcebank.com/), ArticleCentral.com! that monitors and assembles resources constructing a categorized catalog (http://www.articlecentral.com/), and various Harvest libraries (http://www.tardis.ed.ac.uk/harvest/) [20, 21].

Since HDLs are being currently defined, we now present the functional components of our logical harvesting model. The harvesting architecture is composed of the following seven components [22, 23]:

1. Harvester - prepares the harvesting request for the HDL. The harvester provides an interface to the information scientist to achieve this goal. The harvesting request consists initially of a DL profile and a list of URLs. The DL profile contains the DL categories, list of keywords and a set of expected stereotypes of the DL. The given URLs represent the most relevant sites that are known to the information scientist.

2. Locator - receives the initial harvesting request and automatically or semi-automatically expands the URLs list. The Locator can consult with various SEs to expand the harvesting request, and can also enhance the DL profile by using knowledge mana gement techniques.

3. Gatherer - contacts the Internet and Intranet providers in order to gather the prospective resources for the HDL. The gathering is done by recursive descent of all the URLs provided in the harvesting request.

4. Filterer - filters irrelevant documents and passes on only the documents that should be part of the HDL.

5. Summarizer - extracts summaries from the relevant resources and streams them to the Broker.

6. Broker - organizes the set of HDL summaries and builds the various metadata struc tures, such as full index, a topics-tree and relational views of the DL. It can relieve network traffic and solve bandwidth bottlenecks in the Web by using a Harvest Caching Server.

7. Retriever - provides the user with an interface for querying, browsing and touring the HDL.

Table 2 - The Three Generations of Digital Libraries

\begin{tabular}{|c|c|c|c|}
\hline Jeneration No & DLs & Features & Examples \\
\hline 1 & $\begin{array}{l}\text { Stand-alone } \\
\text { SDL }\end{array}$ & $\begin{array}{l}\text { Centralized, } \\
\text { Local, Self- } \\
\text { contained, } \\
\text { Single or } \\
\text { several } \\
\text { collections }\end{array}$ & $\begin{array}{l}\text { Alexandria, } \\
\text { LOC, NDL, } \\
\text { UPL, IPL, } \\
\text { Vlib, ACM } \\
\text { DL }\end{array}$ \\
\hline 2 & $\begin{array}{l}\text { Federated } \\
\text { FDL }\end{array}$ & $\begin{array}{l}\text { Networked, } \\
\text { interoperable }\end{array}$ & $\begin{array}{l}\text { NCSTRL, } \\
\text { NDLTD, } \\
\text { InfoBus }\end{array}$ \\
\hline 3 & $\begin{array}{l}\text { Harvested } \\
\text { HDL }\end{array}$ & $\begin{array}{l}\text { HDL, } \\
\text { Distributed, } \\
\text { Quality } \\
\text { Control, with } \\
\text { Persistence }\end{array}$ & $\begin{array}{l}\text { SourceBank, } \\
\text { ArticleCentra } \\
\text { l.com!, } \\
\text { Harvest }\end{array}$ \\
\hline
\end{tabular}

To emphasize the different aspects of this DL categorization, let us get into the various DL types. In SDL and FDL, the items are electronically purchased or fully digitized/scanned. These items are stored in the local repository (in SDL), or in separate SDL repositories accessed using a network protocol (in FDL). Each SDL (and all together in a F DL) hold a huge repository containing both the items and some metadata structures to enable efficient retrieval. This material is updated every now and then, in a process similar to the one in classical library. It is important to note that composing a FDL out of SDLs requires interoperability capabilities, and the use of a common protocol.

In contrast to the SDL and FDL, the HDL's items are gathered from the network. These items are scattered 
on many servers, and accessed via direct retrieval using standard Internet protocols. The HDL holds only metadata on the items, and therefore its repository is small and compact. Because the items that belong to the HDL can be updated any time by their authors, their summaries have to be dynamically refreshed in the HD L using computerized procedures that are triggered automatically or initiated explicitly by the IS. An interesting point is that the profile of the HDL can be changed by the IS to enhance the library.

An exemplar implementation of the harvesting architecture is the Katsir system [23] (http://bicsir.cs.biu.ac.il:8088/katsir /,

http://bicsir.cs.biu.ac.il:8070/Harvest/brokers/taly/) that is based on the Harvest system. The system includes various tools designed to gather materials and references, while locating resources, extracting metadata on the documents harvested, and indexing them. In order to enrich the access methods available t $o$ the DL user, we developed a topics-tree mechanism. The full implementation of the Katsir system uses the Perl and JavaScript languages. Katsir can be directed to build a focused DL, based on both local and networked harvested materials. And through a use r-friendly interface, the user can retrieve information by keywords or conduct a guided tour by browsing a topics-tree that enables hypertext access to relevant materials.

The Katsir system aims to provide open software architecture for building harvested digital libraries and for intelligent information retrieval. The initial Katsir system was developed and implemented in an educational environment as a response to the unique requirements of the Israeli educational system [22].

\section{The Parallel Evolution}

Both Search Engines (SEs) and Digital Libraries (DLs) are Internet Resource Discovery Tools. We summarize our previous discussion by introducing a resource repositories hierarchy (see figure 1) with two major paradigms: search engines and digital librar ies, where each branches to categories.

\subsection{Analysis of the Parallel Evolution}

To get a broader perspective, it is worthwhile to study how the SEs and DLs paradigms evolved in parallel through the three generations (see table 3 ). The following subsections will continue this study by viewing the forming fourth generation and by extrapolating on the unified fifth generation.
Figure 1 - Resources Repositories Hierarchy

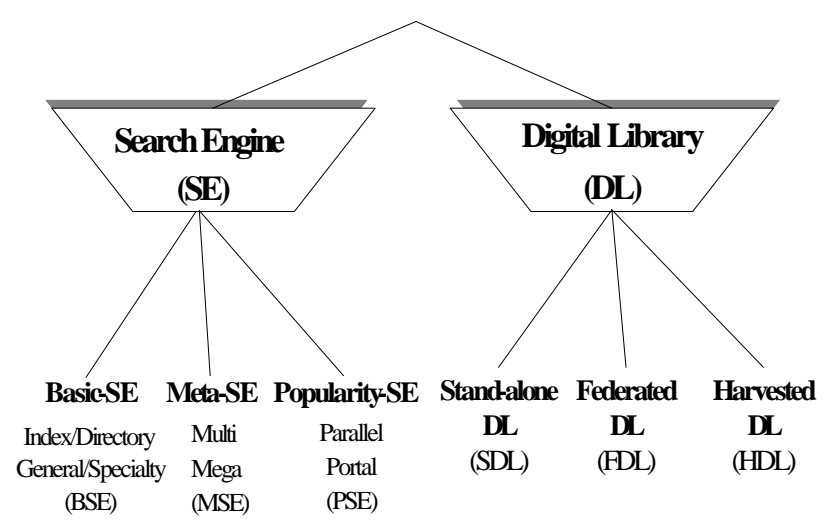

Table 3 - Five Generations of Search Engines and Digital Libraries

\begin{tabular}{|c|c|c|c|}
\hline $\begin{array}{c}\text { Jeneratior } \\
\text { No. }\end{array}$ & SE & DL & $\begin{array}{c}\text { Common } \\
\text { Characteristics }\end{array}$ \\
\hline 1 & Basic-SE & $\begin{array}{c}\text { Stand- } \\
\text { alone DL }\end{array}$ & $\begin{array}{l}\text { Local repositories, } \\
\text { self-contained }\end{array}$ \\
\hline 2 & Meta-SE & $\begin{array}{c}\text { Federated } \\
\text {-DL } \\
(\text { FDL })\end{array}$ & $\begin{array}{l}\text { Multi, networked, } \\
\text { interoperability }\end{array}$ \\
\hline 3 & $\begin{array}{c}\text { Popularity- } \\
\text { SE }\end{array}$ & $\begin{array}{c}\text { Harveste } \\
\text { d-DL } \\
(\mathrm{HDL})\end{array}$ & $\begin{array}{l}\text { Popularity, } \\
\text { parallel, summ aries }\end{array}$ \\
\hline 4 & $\begin{array}{l}\text { Intelligent - } \\
\text { SE (ISE) }\end{array}$ & $\begin{array}{c}\text { Intelligen } \\
\text { t-DL } \\
\text { (IDL) }\end{array}$ & $\begin{array}{l}\text { Integrated services, } \\
\mathrm{AI}, \mathrm{KM}\end{array}$ \\
\hline 5 & \multicolumn{2}{|c|}{ Mega/Meta-Portal } & $\begin{array}{l}\text { Semantic } \\
\text { emphasis, } \\
\text { transparency }\end{array}$ \\
\hline
\end{tabular}

The first generation of both SEs and DLs clearly defined the basic structures of indices, directories and libraries. The vast experimentation carried out centered around how the robots crawl the Web, what to index of the vast Web resources, i.e., generality vs. specialty, how to collect resources in libraries, and the structures of the search interfaces. To demonstrate, many directories were constructed in a search oriented approach, but some took the digital library viewpoint by putting an emphasis on quality control and basic library services. For example, directories referring to themselves as libraries include IPL (www.ipl.org), Vlib (http://vlib.org/), Argus ClearingHouse (http://www.clearinghouse.net/) and many software development libraries.

The second generation could then put the various first generation tools into work. MSEs use several BSEs 
simultaneously to search the Web whereas the FDLs federated related SDLs into a networked library composed of all collections. Both provide their users with a transparent uniform interface to search and browse their combined data repositories. In a sense, they both use a brute force approach by emphasizing quantity massed over the network.

The third generation put the emphasis on various popularity measures such as links, usage and time popularity. Additional characteristics emphasized here include the use of parallel computing power and advanced search techniques. Similarly, the HDL generation, still to materialize, will use popularity measures in its Locator and Fi lterer algorithms.

Note that most members of the first generation SEs have augmented themselves to be third generation SEs. For example, InfoSeek, AltaVista and Excite include analysis tools in their search and browse services. Similarly, HDLs combine ide as from the various first generation SEs and DLs.

This evolutionary process paved the way to the appearance of the Portal (or as it is sometimes called these days, the Enterprise). One can look on the Portals as an ensemble of different SE types in one meeting place in order to provide one-stop enhanced services to their frequent users.

\subsection{The Intelligent Fourth Generation of SEs \& DLs}

The next generation of both SEs and DLs will employ advanced techniques of artificial intelligence and knowledge management [24, 25, 26]. We describe the mechanisms expected in this fourth generation of Intelligent SEs (ISE) and DLs (IDL) using our Harvesting model terminology.

Harvester-Locator:

- Better tools for the construction of the harvesting request and of the focused DL profile.

- Support for a more semantic environment that enables the information scientist to define in a higher-level way the desired data repository to be built.

Gatherer-Filterer:

- Dynamic validation and refresh of summaries to ensure HDL contents preservation.

- More semantic filtering of Web resources based also on the DL profile.

Summarizer-Broker:

o Intelligent information extraction from Web resources, thus giving more meaningful summaries.

- A semi-automatic construction of HDL metadata structures such as a topics-tree and a statistical thesaurus.

Retriever:

- Use of advanced visualization techniques to provide HDL usability and enrich the user experience [27, 28].
- Enhancement of user queries by use of intelligent metadata structures such as a thesaur us (like 'WordNet'

http://www.cogsci.princeton.edu/ wn/), concept maps, ontologies, and user profile enhancement and stereotypes based on users' behavior and feedback [29, 30, 31].

O Provision of knowledge rich library services, such as consultation, users collaboration, contents annotation [32], organizational workflow and routine ERP activities.

An early exemplar of this type of SE is AskJeeves (http://askjeeves.com/) [18] that provides a natural language interface based on a constantly growing knowledge base. Examples of fourth generation SEs include the SurfFax search tool (http://www.surfwax.com/) that supports intelligent composed search, WebArcher intelligent search tool selection (http://www.clearway.com/WebArcher/), Oingo for meaning based search (http://www.oingo.com), Omniget specialized userfocused oriented searching (http://www.omniget.com/) and Fossick meta-search (FMS) for intelligent meta search (http://fossick.com/MetaSearch.htm).

An interesting exemplar of the incorporation of $\mathrm{KM}$ rich services is found in the Perseus DL. Here, toolsets such as a geographical information system (GIS) and a time calculating system, extract structural and descriptive metadata, thus generating timelines of dates and maps of the places mentioned in texts [33].

\subsection{The Fifth Generation of the Mega/Meta Portal}

After the fourth intelligent generation, we see a tendency of convergence to an integrated Mega/Meta Portal that will benefit from the s trengths of both paradigms. The integration will probably first manifest itself in a unified, high -level transparent interface that will be used for declarative search and browse of all data repositories, regardless if they are SEs or DLs. At a later stage we foresee a tendency for even integrating SEs and DLs structures, especially at the metadata structures level.

\section{Conclusions and Further Research}

Throughout this article, we have been answering the four points raised in the introduction. We have been contrasting the types and characteristics of both SEs and DLs, which eventually led us to consider their parallel evolution over the existing three generations and the fourth coming one. In particular, we introduced the idea of the third generation $\mathrm{HDL}$ an $\mathrm{d}$ its resulting $\mathrm{DL}$ harvesting model.

Much research is still needed in how to best integrate the various techniques proposed for digital libraries, information retrieval, warehousing, artificial intelligence and knowledge management in the fourth 
generation intelligent tools. For example, a clear challenge here is to better compose separate HDLs into a virtual HDL that also includes integrated metadata structures and provides a transparent visual user interface, realizing a fourth generation IDL. We foresee a tendency of the eventual convergence of SEs and DLs interfaces and structures in the fifth generation.

\section{Acknowledgements}

The authors are indebted to T. Sharon and Dr. S. Gal for their insightful observations and elucidations, and are grateful as well to the anonymous reviewers who gave valuable and helpful comments.

\section{References}

[1] Schwartz C., "Web Search Engines", Journal of the American Society for Information Science, September 1998, 49(11), pp. 973-982.

[2] Special Issue: Digital Library, Communications of the ACM, April 1995, 38(4).

[3] Special Issue: Digital Library, IEEE Computer, May 1996, 29(5).

[4] Chen H., and A. L. Houston, "Digital Libraries: Social Issues and Technological Advances", Advances in Computers, Academic Press, 48, 1999, pp. 257-314.

[5] Arms W. Y., Digital Libraries, MIT Press, Cambridge, Mass., 2000.

[6] Lawrence S., and C. L. Giles, “Accessibility of Information on the Web", Nature, 400, July 1999, pp. 107-109.

[7] Moore A., and B. H. Murray, "Sizing the Internet: a Cyveillance Study", July 2000, Cyveillance, http://www.cyveillance.com/resources/7921S_Sizing_th e_Internet.pdf

[8] Lassila O., "Web Metadata: A Matter of Semantics", IEEE Internet Computing, July 1998, 2(4), pp. 30-37.

[9] Rust G., "Metadata: the Right Approach", D-Lib Magazine, July/August 1998, http://www.dlib.org/dlib/july98/rust/07rust.htm 1

[10] Peterson R.I., "Eight Internet Search Engines Compared", First Monday, Peer-Reviewed Journal on the Internet, http://www.firstmonday.dk/issues/issue2_2/peterson/.

[11] Lesk M., Practical Digital Libraries, Morgan Kaufmann, San Francisco, 1997.

[12] Kessler J., Internet Digital Libraries, Artech House, Boston, 1996.

[13] Adam N., Y. Yesha et al., "Strategic Directions in Electronic Commerce and Digital Libraries: Towards a Digital Agora", ACM Computing Surveys, December 1996, 28(4), pp. 818-835.

[14] Fox A., and G. Marchionini, "Towards a Worldwide Digital Library", Communications of the ACM, April 1998, 41(4), pp. 29-32.

[15] Waters D.J., "What are digital libraries?", CLIR Issues, July/August, 1998, http://www.clir.org/pubs/issues/issues04.HTML

[16] Waters D. J., "Data and the digital library movement: Where do we go from here? The Digital Library Federation and numeric data", IASSIST '99, May 21, 1999.
[17] Hackathorn R. D., Web Farming for the Data Warehouse, Morgan Kaufmann, San Francisco, 1999.

[18] Clark D., "Natural Language, Relevancy Ranking and Common Sense", IEEE Intelligent Systems, July/August 1999, 14(4), pp. 17-19.

[19] Paepcke A., et al., "Using Distributed Objects to Build the Stanford Digital Library Infobus", IEEE Computer, February 1999, 32(2), pp. 80-87.

[20] Bowman C. M., et al., "Scaleable Internet Resource Discovery: Research Problems and Approaches", Communications of the ACM, 37(8), August 1994, pp. 98-107.

[21] Bowman C. M., et al., "Harvest: a Scaleable, Customizable Discovery and Access System", Dept. Computer Science, Univ. Colorado, TR CU-CS-732-94, March 1995.

[22] Hanani U., and A. Frank, "Intelligent Information Harvesting Architecture: an Application to a High School Environment", Online Information 96, London, December 1996, pp. 211-220.

[23] Hanani U., and A. Frank, "Katsir: A Framework for Harvesting Digital Libraries on the Web", ECIS 2000 Proceedings, Vienna, July 2000, pp. 306-312.

[24] O'Leary D. E., "Enterprise Knowledge Management", IEEE Computer, March 1998, 31(3), pp. 54-61.

[25] O'Leary D. E., "Using AI in Knowledge Management: Knowledge Bases and Ontologies", IEEE Intelligent Systems, 13(3), May/June 1998, pp. 34-39

[26] Yeh J.H., J. Y. Chang, and Y. J. Oyang, "Content and Knowledge Management in a Digital Library and Museum", Journal of the American Society for Information Science, March 2000, 51(4), pp. 371-379.

[27] Terveen L., W. Hill, and B. Amento, "Constructing, Organizing, and Visualization Collections of Typically Related Web Resources",ACM TOCHI, 6(1), March 1999, pp. 67-94.

[28] Crimmins F., et al., "TetraFusion: Information Discovery on the Internet", IEEE Intelligent Systems, July/August 1999, 14(4), pp. 55-62.

[29] Shapira B., P. Shoval, and U. Hanani, "Stereotypes in Information Filtering Systems", Information Processing \& Management, 1997, 33(3), pp. 273-287.

[30] Shapira B., P. Shoval, and U. Hanani, "Experimentation with an Information Filtering that Combines Cognitive and Sociological Filtering Integrated with User Stere otypes", Decision Support Systems, 27, (1999), pp. 5-24.

[31] Special Issue: Overlapping Metadata Standar ds, Journal of the American Society for Information Science, November 1999, 50(13).

[32] Fraenkel A. P., and S. T. Klein, "Information Retrieval from Annotated Texts", Journal of the American Society for Information Science, 50(10), pp. 845-854, 1999.

[33] Rydberg-cox J. A., et al., "Knowledge Management in the Perseus Digital Library”, Ariadne, Spetember 2000, no. 25 , http://www.ariandne.ac.uk/issue25/rydberg cox/intro.html. 